\begin{tabular}{|c|c|}
\hline ב & $\begin{array}{c}\text { International Journal of Current Research } \\
\text { and Academic Review }\end{array}$ \\
\hline $\begin{array}{l}\text { XCELLENT } \\
\text { XCELERS }\end{array}$ & $\begin{array}{r}\text { ISSN: 2347-3215 (Online) } \because, ; \text { Volu } \\
\text { Journal homepage: }\end{array}$ \\
\hline
\end{tabular}

doi: https://doi.org/10.20546/ijcrar.2017.511.002

\title{
Correlation of Apgar Score to the Eruption Status of the Primary Dentition - A Cross Sectional Study
}

\author{
Manisha Agarwal, Devi Vegesana* and Sapna Konde
}

\begin{abstract}
AECS Maaruti Dental College, 108, Hulimavu Tank Band Road, Off Bannerghatta Road, BTM 6th stage, 1st phase, Kammanhalli, Near Meenakshi Temple, Bengaluru-560076, Karnataka, India
\end{abstract}

*Corresponding author

\section{Abstract}

The main aim of this study was to correlate the Apgar score to the eruption status of the primary dentition in six-thirty six months child. Objective: 1) Collection of Apgar score 2) To evaluate the eruption status of the deciduous teeth and to compare the same with the standard data -Lunt \& Law 1974. 3) To determine the effect of variation in Apgar Score on eruption status. Settings and Design: The study was conducted on 103 infants and toddlers in the age group of six to thirty six months in various government and private hospitals in Bangalore. Methods and Material: The study was done on 103 children, whose demographic data and APGAR score were collected. Dentition status was recorded in FDI system. The collected data was tabulated and subjected to statistical analysis. Statistical analysis used: Chi-square test was used to analyse categorical data, mannwhitney u test was used to assess the variation in eruption status with Apgar score. Results: Out of 103 samples, 21 children with less Apgar score, seven $(33.33 \%)$ had delayed in eruption and out of 82 with normal Apgar score only five $(6.1 \%)$ had delayed eruption. This difference was statistically significant. $\mathrm{P}=0.001$ Conclusions: The study concluded a significant association of low Apgar score and delayed eruption. Thus readily accessible markers of early life, (Apgar score), may guide clinicians in identifying children with a higher risk for delayed eruption and aid in decision making in allocating preventive services for the same.
\end{abstract}

\section{Introduction}

Eruption of teeth is considered as one of the important milestones in the child's development. ${ }^{1}$ The age of eruption of primary teeth has long been of interest in biological, physical and anthropological studies. ${ }^{2}$

Tooth eruption is defined as the movement of the tooth from its site of development in alveolar bone to the occlusal plane in the oral cavity. ${ }^{3}$ The eruption process is complex and many different mechanisms are involved. It

\section{Article Info}

Accepted: 28 October 2017

Available Online: 20 November 2017

\section{Keywords \\ Apgar score, \\ Delayed eruption, \\ Eruption schedule.}


and need for prompt intervention to establish breathing. 11 Apgar Index (AI) is utilized for the evaluation of general, neural and behavioral status of newborns. 12 It is a measure of the vitality of the infant on the basis of heart rate, respiration, color, muscle quality, and reflex excitability.

It is one of the first indices used for early diagnosis of infant anomalies. The technique involves first to fifth min assessment of skin colour, heartbeats, muscular tonicity, primary motor reflex and rate of respiration. The Apgar index value of seven to ten is considered normal, whereas a value of < six indicates special medical Measures. ${ }^{13}$

Previous literature suggests that Apgar index is inversely correlated with enamel defects of primary teeth. Both quality and quantity of enamel defects of primary dentition are higher in children with lower Apgar index. ${ }^{13}$ Study in Indian population shows, subjects with lower Apgar Index exhibited more hypoplastic and hypocalcified teeth both qualitatively and quantitatively. ${ }^{14}$ Another study in 2010 by Sander et al., said that low Apgar score was associated with compromised immune development and lowered resistance to infection that may increase susceptibility to dental decay. ${ }^{15}$

Estimation of eruption schedule can be a truly valuable asset in diagnosis and treatment planning during developmental years, including the diagnosis of developmental oral disturbances during the early childhood periods. Dental age is the key component for the implementation of caries prevention programs such as topical fluoride application, age estimation in forensic sciences and anthropology. Dental development is also significant because the number of primary teeth that have erupted is frequently used for chronological age assessment of young children in communities where exact birth dates are not experienced.

Due to the lack of literature on correlation between Agar score and eruption status of the primary dentition. Our study was contemplated with the same purpose.

Objectives Of The Study:

To Collect the recorded Apgar score.

To evaluate and compare the eruption status of the deciduous teeth with the standard data - Lunt \& Law $1974 .^{16}$
To determine the effect of variation in Apgar Sore on the eruption status of primary teeth.

\section{Materials and Methods}

The study was conducted on 103 infants and toddlers in the age group of six to thirty six months in various government and private hospitals in Bangalore.

\section{Inclusion criteria}

Subjects with recorded Apgar score.

Full term infants.

\section{Exclusion criteria}

Pre term infants.

Children, born from complicated pregnancies and deliveries;

Presence of any hereditary diseases.

Presence of natal and neonatal teeth.

Prior consent was obtained from parents of the infants and toddlers of both the genders who were included in the study. The data regarding the Apgar Index of the subjects was recorded by referring to the natal and neonatal history. A specially designed proforma was used to collect information on demographic characteristics and the timing at which the first tooth erupted was recorded.

The investigator conducted the clinical examination of all the participating children. It was performed under good illumination under natural day light with disposable mouth mirror and tongue blade with the subject seated on their parents lap. When required a battery operated torch (artificial illumination) was used.

All partially and completely erupted teeth were noted and recorded. Each deciduous tooth was recorded using two digit system of Federation Dentaire International notation. The emergence stages of the teeth into the oral cavity are classified into four stages.

The stages are defined as

Stage Zero $=$ The tooth is not visible in the oral cavity .

Stage One $=$ At least one cusp visible in the oral cavity . 
Stage Two $=$ The entire occlusal surface or mesio - distal width of the tooth is visible.

Stage Three $=$ The tooth in occlusion or at occlusal level if the antagonistic tooth was not fully erupted or missing.

In this study, tooth was recorded as erupted when any part of the crown is visible through the oral mucosa (stages one, two and three). All the data were compiled and tabulated. Comparison was made between the data obtained and the standard data (LUNT AND LAW 1974). ${ }^{16}$

The obtained data was subjected to a relevant statistical analysis. Chi - square test was used to analyse categorical data, mannwhitney u test was used to assess the variation in eruption status with Apgar score.

\section{Results and Discussion}

Out of 103 individuals incorporated in the study, with the age group ranging between six-thirty six months, 59 were males and 44 were females.

Table A.1 shows comparison of Apgar Score and eruption status, with a $\mathrm{P}$ value of 0.006 (statistically significant). Out of 103, 12 had a delayed eruption with mean Apgar Score of 7.50 and 91 had normal eruption with mean Apgar Score of 8.34.

According to Table A.2, seven (33.3\%) children out of 21 having < seven Apgar Score showed delay in eruption and other 14 showed normal eruption. In the remaining 82 subjects with > seven Apgar Score, five (6.1\%) had delayed eruption and 77 had normal eruption. The comparison between the children with delayed eruption showed significant difference indicating the increased risk of delayed eruption in children with lesser Apgar Score.

The time of calcification and eruption of deciduous teeth is subjected to several individual variants. 17 Significant deviations from accepted norms of eruption times are frequently discovered in clinical practice. Premature eruption has been observed, but delayed tooth eruption is the most frequently encountered. ${ }^{18}$

There are many reasons for delayed tooth eruption which include, local drives such as lack of space, ankylosis of teeth, gingival firbromatosis, supernumerary teeth, cysts and neoplasms. The systemic factors which meet a role are endocrinopathies, syndromes, inherited disorders, neurological disorders, etc. Based on Apgar Scoring system, infants are observed systematically at birth for their requirement of immediate concern. Prediction of long - term outcomes was never a goal of the Apgar Scoring system research. Nevertheless; it provides inceptive documentation for considering the long term effects of any type such as developmental and neurological.

This study was enrapt to investigate if any correlation exists between Apgar Score to the eruption status of the primary dentition. Our findings indicate a strong correlation $(p=0.001)$ of Apgar Score to the eruption status of the primary dentition. However, the effect of age and gender on distribution of eruption as a covariant was not statistically significant.

Table.1 Comparison of Mean APGAR score with eruption status

\begin{tabular}{|l|l|l|l|l|}
\hline Eruption & $\mathrm{N}$ & Mean & Std. Deviation & T test \\
\hline Delayed & 12 & 7.50 & 1.45 & $\mathrm{p}=0.006$ \\
(Significant)
\end{tabular}

Table.2 Distribution of study subjects by APGAR score category \& eruption status

\begin{tabular}{|l|l|l|l|l|l|}
\hline \multicolumn{2}{|c|}{} & \multicolumn{2}{|c|}{ Eruption status } & \multirow{2}{*}{ Thisquare test } \\
\cline { 3 - 5 } \multicolumn{2}{|c|}{} & Delayed & Normal & \\
\hline $\begin{array}{l}\text { APGAR } \\
\text { score } \\
\text { category }\end{array}$ & $\leq 7$ & $7(33.33)$ & $14(66.67)$ & $21(100)$ & $\begin{array}{l}\text { P }=0.001 \\
\text { (Significant) }\end{array}$ \\
\cline { 1 - 4 } Total & $5(6.1)$ & $77(93.9)$ & $82(100)$ & \\
\hline
\end{tabular}


A case - control study in Denmark found that a low five min Apgar score was associated with increased risk for autism, increased risk of hospitalization for epilepsy and for pneumococcal disease by the age of 12 years. ${ }^{19-21} \mathrm{~A}$ low one min Apgar score was associated with increased odds of asthma by the age of three years. ${ }^{22}$ A study on Norway on 5,00,000 babies indicated that low apgar score were strongly associated with cerebral palsy in children of normal birth weight and modestly in children of low birth weight. ${ }^{23}$ Low birth weight and immaturity are closely related to the risk of cerebral palsy and are also associated with the a low Apgar score. ${ }^{23}$ In the study by Jancy et al., in 1991, the data collected for dmf and DMFT revealed significantly more unerupted primary teeth in CP children below six years old and permanent teeth in those ages 11 years and above ${ }^{24}$. Thus, our study revealed, Apgar Score is inversely correlated to the delayed eruption of primary teeth.

The importance of the delayed tooth eruption as a clinical problem is well reflected by a number of published reports on the issue. It might be a primary or only manifestation of local or systemic pathology that can cause occlusal, functional and aesthetic problem. Therefore, it is proposed to extend out more intense and stringent oral screening for the subjects with Apgar values of $<7$.

Effect of age and gender on the distribution of eruption as a covariant was not statistically significant. Further research may be focused towards the investigation of the association of the Apgar Score to the eruption status of the deciduous teeth in a larger number of individual and mechanism behind it. Furthermore, the study of the association of growth and development, craniofacial and musculoskeletal anomalies with AI also seem to be interestingly exciting.

Managing delayed tooth eruption is challenging to the Paediatric Dentist because of it causes functional and occlusal problem with the children. Furthermore, if it is not treated on time, it bears on their quality of liveliness.

From this study, it may be concluded that there is a significant association of low Apgar Score with delayed eruption. Thus, through this study we would suggest that it can be included as one of the parameter in the past medical history which may guide clinicians in identifying children with higher risk for delayed eruption and aid in decision making in allocating preventive services for the same. The outcomes of the study also indicates, a need that even exists for the better specialty care of youngsters with high risk group so that their dental health may be bought up to and maintained at the stratum of that provided for other children.

\section{Acknowledgement}

I am very proud to be the daughter of my parents $\mathrm{V}$ Srinivas Raju \& V Padma vathi who has been my role model. I would like to extend my gratitude to my husband K Chandra Mouli Raju for his support. I would like to extend heartfelt thanks to my sister Sirisha and my uncle V Surya Narayana Raju for their constant encouragement \& motivation. I would like to thank my fellow batchmates Dr Umadevi \& Dr Suryoday helping in completing the study.

\section{Formatting of funding sources}

This research did not receive any specific grant from funding agencies in the public, commercial, or not-forprofit sectors.

\section{Ethical clearance}

Work has been approved by the ethical committees of AECS Maaruti dental college and Research centre, bangalore in which it was performed and that subjects gave informed consent to the work.

\section{References}

1. Lavelle CL. A note on the variation in the timing of deciduous tooth eruption. Journal of dentistry. 1975 Nov 1;3(6):267-70.

2. JELLIFFE EP, JELLIFFE DB. Deciduous dental eruption, nutrition and age assessment. Journal of Tropical Pediatrics. 1973 Jun 1;19(supp2A):193248.

3. Sarveshu G, kirtanya BC, Guptha KK, et al., Delayed teeth eruption, A mirror to systemic deficiency of vitamin D. Indian journal of dental sciences : 1(7), 2015

4. Goran K, Sven P. Pediatric Dentistry :A clinical approach. 2nd edn.Wiley Blackwell.

5. Infante PF, Owen GM. Relation of chronology of deciduous tooth emergence to height, weight and head circumference in children. Archives of oral biology. 1973 Nov 30;18(11):1411-7.

6. Trupkin DP. Eruption patterns of the first primary tooth in infants who were underweight at birth. ASDC journal of dentistry for children. 1973 Dec;41(4):279-82. 
7. Delgado H, Habicht JP, Yarbrough C,et al., Nutritional status and the timing of deciduous tooth eruption. The American journal of clinical nutrition. 1975 Mar 1;28(3):216-24.

8. Demirijian A, Falkner F, Tanner JM. Dentition in human growth, Volume 2, Postnatal growth.

9. Demirjian A, Levesque GY. Sexual differences in dental development and prediction of emergence. Journal of dental research. 1980 Jul;59(7):1110-22.

10. Fadavi S, Punwani IC, Adeni S, et al., Eruption pattern in the primary dentition of premature lowbirth-weight children. ASDC journal of dentistry for children. 1992;59(2):120-2.

11. Apgar V. A proposal for a new method of evaluation of the newborn. Classic Papers in Critical Care. 1952;32(449):97.

12. American Academy of paediatrics, Committee on fetus and New born; American College of Obstetricians Practice. The Apgar score. 2006; 117:1444-1447

13. Aminabadi NA, Farahani RM, Gajan EB. Apgar index as a correlate of enamel defects of primary dentition. Oral health \& preventive dentistry. 2008 Sep 1;6(4).

14. Nirmala SV, Quadar MA, Veluru S, et al., Apgar index as a probable risk indicator for enamel defects in primary dentition: A cross sectional study. Journal of Indian Society of Pedodontics and Preventive Dentistry. 2015 Jul 1;33(3):229.

15. Sanders AE, Slade GD. Apgar score and dental caries risk in the primary dentition of five year olds. Australian dental journal. 2010 Sep 1;55(3):260-7.

16. Lunt RC, Law DB. A review of the chronology of calcification of deciduous teeth. The Journal of the
American Dental Association. 1974 Sep 1;89(3):599-606.

17. GunaShekhar M, Tenny J.Longitudinal study of age and order of eruption of primary teeth in Indian children. J ClinExp Dent 3(2): e113-116,2010.

18. Faizal CP. Delayed Tooth Eruption.e-Journal of Dentistry 2011 Oct-Dec 1(4):81-86.

19. Larsson HJ, Eaton WW, Madsen KM,et al., Risk factors for autism: perinatal factors, parental psychiatric history, and socioeconomic status. American journal of epidemiology. 2005 May 15;161(10):916-25.

20. Ehrenstein V, Sørensen HT, Pedersen L,et al., Apgar score and hospitalization for epilepsy in childhood: a registry-based cohort study. BMC Public Health. 2006 Feb 1;6(1):23.

21. Mahon BE, Ehrenstein V, Norgaard M,et al., Perinatal risk factors for hospitalization for pneumococcal disease in childhood: A Populationbased cohort study. Pediatrics 2007;119:e804-812.

22. Metsälä J, Kilkkinen A, Kaila M, et al., Perinatal factors and the risk of asthma in childhood-a population-based register study in Finland. American journal of epidemiology. 2008 May 28;168(2):170-8.

23. Lie KK, Grøholt EK, Eskild A. Association of cerebral palsy with Apgar score in low and normal birthweight infants: population based cohort study. Bmj. 2010 Oct 7;341:c4990.

24. Pope JE, Curzon ME. The dental status of cerebral palsied children. Pediatric dentistry. 1991; 13(3):156-62.

\section{How to cite this article:}

Manisha Agarwal, Devi Vegesana and Sapna Konde. 2017. Correlation of Apgar Score to the Eruption Status of the Primary Dentition â€“" A Cross Sectional Study. Int.J.Curr.Res.Aca.Rev. 5(11), 7-11.

doi: https://doi.org/10.20546/ijcrar.2017.511.002 